\title{
Lecturer Formative Feedback Preferences: The Influence of Disciplines
}

\author{
Chan Chang-Tik ${ }^{1}$ \\ ${ }^{1}$ Campus Education Excellence, Monash University Malaysia, Selangor, Malaysia \\ Correspondence: Chan Chang-Tik, Campus Education Excellence, Monash University Malaysia, Jalan Lagoon \\ Selatan, 47500 Bandar Sunway, Selangor, Malaysia.
}

Received: August 27, 2019

Accepted: September 30, 2019

Online Published: November 15, 2019

doi:10.5539/ies.v12n12p1

URL: https://doi.org/10.5539/ies.v12n12p1

\begin{abstract}
This study attempts to determine the choice of the feedback model related to discipline categorised as hard-applied, soft-applied, hard-pure and soft-pure. It also attempts to explore the extent in which the lecturers practise socio-constructivist feedback. It was a non-experimental study conducted in an offshore campus in Malaysia of an established Australian university. The data were collected by six research assistants through semi-structured interviews involving 31 lecturers from all the seven Schools in the university. The data were transcribed and analysed using the framework method as a form of thematic analysis. Since it was a deductive study, academic disciplines were used as pre-selected themes and in each feedback category, there were pre-defined codes. The results reveal that there is no serious evidence to link discipline to the choice of feedback model. In addition, lecturers do practise socio-constructivist feedback as well as other variants of feedback.
\end{abstract}

Keywords: socio-constructivist feedback, cognitivist feedback, discipline, higher education

\section{Introduction}

One of the common complaints from students in their evaluation of university teaching is the lack of feedback they received. Specifically, the issue seems to be that the feedback given is not structured to target certain learning outcomes, and that students do not know how to exploit it in order to further improve their work. To this end, universities have put effort into enhancing the quality of feedback, particularly, in the areas of clarity, structure and relevance. Although quality feedback has been found to be important, it still does not result in improved student learning (Wingate, 2010). To achieve effective results, interaction among lecturers, students and disciplinary content should be structured effectively (Garrison \& Cleveland-Innes, 2005). However, with reference to the rising student numbers in higher education and the current resource constraints, one can observe that all of these is putting a strain on the ever-increasing lecturers' workload. Therefore, using a qualitative approach, the current study explores interactions between lecturers and students, and student-to-student under different feedback models (cognitivist and socio-constructivist) and different categories of discipline (hard-applied, soft-applied, hard-pure and soft-pure). Regarding the cognitivist feedback, overall, it is more stressful for the lecturers and consumes more time to implement. This is because it is more directive and corrective in nature with the lecturers delivering the feedback to the passive students. In contrast, the socio-constructivist feedback is more facilitative, involving dialogue among the peers to act on the comments and suggestions given in order to come up with new understanding and hence the burden does not solely rest upon the lecturers (Archer, 2010).

A glance at the literature reveals that there is a paradigm shift in instruction towards a student-centred approach. A few studies in the literature note that disciplinary effects may have a strong influence on student satisfaction with online learning, but they may not have a large impact on the learning outcomes (Arbaugh, 2005). In a similar vein, some studies done with forty online MBA courses reveal that disciplinary effects account for $67 \%$ of the variation in student satisfaction in instructional delivery (Arbaugh \& Rau, 2007). Even though previous research admits the importance of disciplinary effects, further research is needed that can systematically establish a link between the disciplines and feedback models.

In the quest to work assiduously towards achieving student-centred teaching and learning, there should be a theoretical shift in feedback from the 'telling' or 'delivery' paradigm to the socio-constructivist paradigm. Importantly, Nicol (2010) argues that feedback should be conceptualised as a dialogue so that students can construct meaning from the received message, analyse it, and discuss it with others. In this context, it implies that 
feedback can come from peers, the Internet and external experts, and likewise from the lecturers themselves. It is important to note here that students gain more in giving feedback than in receiving, it develops students' capabilities towards being independent and reduces their dependence on the lecturers for feedback (Nicol, Thomson, \& Breslin, 2014). Even though peer feedback is not the focus of this study, the socio-constructivist feedback requires interactions among peers.

In the current study, the academic disciplines are conceptualised as 'hard' and 'soft' as well as 'pure' and 'applied' (Biglan, 1973). In other words, disciplines with well-developed paradigms would be 'hard', whereas those with underdeveloped paradigms would be 'soft'. Accepting this classification of disciplines, Arbaugh, Bangert, and Cleveland-Innes (2010) explain that the hard-applied disciplines call for progressive mastery of techniques in linear sequences based on factual knowledge, while the teaching and learning activities are more focused and instructive. In contrast, the soft-applied disciplines tend to be free-ranging, and their teaching and learning activities tend to be constructive and reiterative. Given all the insights above, in the present study, it is reasonable to assume that of the disciplines from the School of Engineering are categorised as hard-applied, while the majority of the disciplines from the School of Business and the School of Pharmacy fall under soft-applied. As for the pure disciplines, Feibleman (1972) indicates that the word 'pure' implies knowing whereas 'applied' implies action. In this regard, he also concludes that a discipline can exist somewhere in between, that is, to some degree both pure and applied. Still though, employing the conceptualisation of disciplines as mentioned, the School of Arts and Social Sciences and the School of Information Technology contribute mainly to the soft-pure category, and the School of Science and the School of Medicine and Psychology add to the hard-pure disciplines.

\section{Literature Review}

\subsection{Cognitivist Feedback}

Historically, in cognitivist feedback, lecturers correct the students' work with regard to the mistakes made with the intention that they should apply the corrections to make progress in their studies. Indeed, this notion of feedback has a strong behavioural emphasis that focuses on the external provision of information based on observable performance (Boud \& Molloy, 2013). In this context, feedback becomes synonymous with 'telling', that is, it is a one-way transmission of information from the lecturers to the students. There remains, however, a degree of uncertainty regarding how the students should act on their feedback to improve their performance while believing the information transmitted is sufficient for such a change to occur. In order to achieve effective results, the completion of a feedback loop is essential in order to adjust the actions a lecturer would need to take to ensure an impact on student learning.

Speaking of the feedback loop, it leads to another variation of feedback that requires the lecturers to generate continual information to meet the learning needs of the students. In other words, the onus is on the lecturers to ensure that the feedback provided has an effect and to notice the effect. However, according to Boud and Falchikov (2007) this variation of feedback is not sustainable because of resource constraints and the expectation of not 'spoon-feeding' students. Additionally, it may need more than one cycle of feedback to reach the desired end for highly 'unachievable' learning outcomes, or less-responsive students (Boud \& Molloy, 2013). Therefore, any attempt to accept this feedback educationally, it should be used selectively, for instance, in disciplines that require these kinds of forensic interventions into students' learning like basic writing (soft-pure discipline), and analytical skills in particular kinds of problem-solving (certain hard-applied discipline).

Based on the insights above, it is reasonable to assume that this variant of feedback still fits into the paradigm of one-way information transmission from the lecturers to the students. It only varies in the requirement of ensuring that students act upon the information received. To this end, Boud and Molloy (2013) state that the main limitation of this feedback model is the assumptions it makes that students depend on others to provide information they need to learn, that is, students cannot self-regulate their learning. Specifically, given the requirements of the feedback models, there is need to re-assess how students learn and the roles lecturers play to help them acquire feedback literacy, which consists of four main features, namely appreciating feedback, making judgments, managing affect, and taking action (Carless \& Boud, 2018). Accordingly, it would be beneficial to provide a spectrum to relate the variants of feedback. To serve this purpose, on one end of the spectrum is the cognitivist feedback with the socio-constructivist feedback at the other end. In between, one variant that requires a feedback loop is placed closer to the cognitivist side and the other, sustainable feedback is closer to the socio-constructivist. From the spectrum perspective, the purpose of the present study is to present the lecturers preferences of the feedback models in relation to the disciplines they teach.

\subsection{Socio-constructivist Feedback}

As the conceptions of feedback move from the mechanistic to the responsive, feedback becomes a process that 
students used to facilitate their learning. To illustrate, Carless, Salter, Yang, and Lam (2011) build on Hounsell (2007) notion of sustainable feedback and extend it to include some characteristics of self-regulated learning (monitoring and evaluating self-learning and goal setting and planning of learning). In this regard, the other remaining characteristics involve the functions of lecturers to engage students in dialogue about learning, to design assessment tasks that engage students, and to enhance their performance. It is noteworthy that the sustainable feedback model needs the contributions from both the lecturers and students to function. Specifically, the lecturers have to design learning activities to facilitate students learning and even develop the educative purpose of assessment for students to practise peer and self-assessment. Here, students rarely enter courses prepared for this, therefore, it is also important to help them develop their self-regulatory skills, and to assist them to view feedback as a means to increase their capability in making judgements and acting upon them.

In terms of increasing the effectiveness of socio-constructivist feedback, Carless et al. (2011) emphasize the need for students to engage in dialogue to monitor their work, to make judgment and plan their learning, and subsequently to discriminate what is quality performance and enact it. In this respect, dialogue is taken to include all forms of interactions between students and lecturers, between peers, practitioners and learning systems. Importantly, dialogue is not just one-to-one conversations, but one-to-many as well. By doing this, the tendency to share through dialogue, sense making and co-construction between peers (Price, Handley \& Millar, 2011) contributes to interactions that are more meaningful between peers.

Further, in a study by Nicol et al. (2014) involving 82 students from the first-year Engineering Design class (hard-applied discipline), the result is that peer assessment is beneficial. The socio-constructivist feedback gives the students the opportunities to construct meaning from feedback provided by others as well as to learn from feedback meanings they construct for others. According to the students in Nicol's study, if they have more openings to engage in acts of critical appraisal, it may eventually reduce the need for feedback from peers and even lecturers. Of note, these findings are of particular significance to the current study that attempts to determine the link between the discipline and the types of feedback lecturers prefer.

Given all the insights above, it is reasonable to assume that peer assessment is of utmost importance for the socio-constructivist feedback. This assumption suggests that, for the socio-constructivist feedback to be successful, there is a need to emphasise on many engagement initiatives to gain students' active participations in group-work. However, this alone may not be sufficient to build the capacity of the students to benefit from the feedback. They have to see themselves as agents of change and drive their own learning, that is, to be engaged in self-regulation of their learning (Nicol \& Macfarlane-Dick, 2007).

It is clear from the evidence in the literature; feedback should be repositioned to become a key curriculum space for communicating, for knowing, for judging, and for acting (Boud \& Molloy, 2013). In other words, from early in the programme, students need to know they have to make judgments about their own work and as well of others, to make self-appraisal and compare it with appraisal by others. Therefore, feedback cannot be taken for granted as something lecturers do, any more than it is something students do themselves. Accordingly, Carless and Boud (2018) take it a step further to include feedback literacy in curriculum designs and to embed it systematically throughout the programmes for effective implementation.

In what follows, this paper provides a qualitative data analysis to gain more insights into the mapping of feedback models (dependent variable) to disciplines (independent variable) in higher education by addressing the following research questions:

1) Do lecturers practise socio-constructivist feedback?

2) Is the choice of feedback model related to discipline? If so, how?

\section{Methodology}

This investigation employed a basic qualitative research method that included collecting quotes from the lecturers, and verifying them with the purpose of answering the research questions (Vanslambrouck, 2019). The study took place in an offshore campus in Malaysia of an established Australian university. The University has about 350 academic staff and approximately 8,000 students. To answer the research questions, six research assistants conducted in-depth, semi-structured interviews. All the research assistants assigned to administer the interviews were trained by the chief investigator on probing questions to ask based on the responses received. The interview questions were in line with the seven principles of good feedback practice by Nicol and Macfarlane-Dick (2007). To illustrate the questions on the focus of feedback are in line with the principle of delivering high quality information to students about their learning. As for the outlooks of feedback, the emphasis is on the principle of encouraging teacher and peer dialogue around learning. Finally, with regard to the preferences of feedback the 
focus is on the principle of facilitating the development of self-assessment (reflection) in learning.

The questions were designed to obtain information on:

(a) The lecturers' focus of feedback: Describe the nature of feedback provided to students, that is, in terms of strengths and weaknesses, and corrective advice that directs students to higher order learning goals.

Example: If feedback given is directly linked to marks and final examination, do you think it will support student learning?

(b) The lecturers' outlooks of feedback: Describe the opportunities for informal feedback as in peer collaboration so the received feedback is part of the teaching and learning process.

Example: How do you create a learning environment for students to challenge and contest others on their views?

(c) The lecturers' preferences of feedback: How do you conceptualise feedback, is it as a dialogue or as an information transmission?

Example: How do you deliver constructive feedback to your students?

\subsection{Subjects}

The lecturers were selected from seven Schools (School of Engineering, School of Science, School of Medicine and Psychology, School of Business, School of Pharmacy, School of Information Technology and School of Arts and Social Sciences) through a stratified sampling method. More specifically, to capture the diversity of the lecturers in each School, at least one lecturer from each discipline was sought for an interview. Lecturers were contacted randomly and to ensure data reliability and valid results, eight lecturers each were contacted from the School of Engineering and the School of Business because both Schools had a bigger enrolment in terms of student and academic staff numbers. As for the remaining five Schools, three lecturers each were contacted, giving a total of 31 lecturers. The courses taught by the participating lecturers were classified as follows:

Hard-pure: Thermodynamics and Heat Transfer, Mechanics of Fluids, Molecular Biology and Biotechnology, Neurology and Oncology

Soft-pure: Physiology and Anatomy, A World in Crisis, Contemporary Feminism in Asia, Introductory Microeconomics, Web Fundamentals

Hard-applied: Design of Steel and Timber Structure, Computing for Engineers, Auditing and Assurance, Introduction to Financial Accounting, Management Accounting

Soft-applied: Medicine 1, Public Health, Principles of Forecasting and Applications, Integrated therapeutics: Infectious disease, Mobile Application Development

All the lecturers had more than three years of teaching experience. The demographics of the lecturers were as follows: $43.3 \%(n=13)$ of the subjects were female and $56.7 \%(n=17)$ were male; $67.7 \%(n=21)$ were Malaysian; and the majority of them were more than 30 years old $(93.3 \%, n=28)$.

\subsection{Data Collection}

After an initial training, the research assistants approached the lecturers, and explained the purpose of the study to them. Subsequently, each of them was given the research explanatory statement. In about a week's time, the research assistants returned and upon receiving consent from the lecturers, arrangements were made to conduct the semi-structured interviews. In the event the lecturer turned down the request, the research assistant contacted randomly another lecture of the same discipline.

Each interview session was scheduled for 45-60 minutes. It was audio recorded with permission in the respective lecturer's faculty room. Two lecturers were not comfortable to respond to some questions asked, and hence they chose to ignore them. While, another group of five lecturers opted to break the interview session into a few other sessions.

The interview data were organised into three main categories, that is, focus of feedback, outlooks of feedback and preferences of feedback.

\subsection{Data Analysis}

Data from the interviews were transcribed and analysed using the framework method (Gale, Heath, Cameron, Rashid, \& Redwood, 2013) as a form of thematic analysis. Since it is a deductive study, the researchers first listened to the interview recordings, read the transcripts, and thought about the pre-defined codes in each category of feedback. More specifically, under the focus of feedback category the data were coded as types of feedback, reasons for feedback, nature of feedback and corrective advice given. Similarly, for the outlooks of feedback 
category, the code was on how informal feedback was given as in peer collaboration. Finally, for the preferences of feedback category, the codes were the reasons for choosing dialogue or information transmission feedback and peer dialogue among students. Second, using Biglan (1973) conceptualisation of academic disciplines as pre-selected themes and together with the feedback category codes, the researchers analysed the interviews. To ensure coding reliability, the interrater reliability should have a substantial agreement with Kappa $=0.71, \mathrm{p}<0.001$ (McHugh, 2012). In this context, two distinct researchers to ensure consistency of qualitative data checked codes thus established.

\section{Results}

Findings from the interviews are presented in each area of functioning. Tables 1-4 give an overview of the lecturers' thoughts regarding the focus, outlooks and preferences of feedback in accordance to each discipline cluster. Additionally, detailed explanations of the lecturers' thoughts are provided by giving lecturer quotes in each category of feedback.

\subsection{Soft-Pure Discipline}

As can be seen in Table 1, the majority of the lecturers prefer to give feedback in the dialogue mode, but the conversation is mainly between them and the students and only in two cases, student-to-student. To this end, informal feedback is not a popular choice. Surprisingly, lecturers also do not focus much on corrective advice that directs students to higher order learning goals.

In the focus of feedback category, the qualitative findings show that feedback from lecturers MP01 and BU01 take the form of written comments on an assignment task. Occasionally, MP01 organises a chatroom for a closed-group of students in order to give a quick feedback to them. Of note, AS03 uses the features on Microsoft Words to 'comment on the students submissions based on the assessment rubrics.' Besides written feedback, MP01 students receive demonstrative advice by trained clinicians to teach them hands-on skills like 'how to operate equipment and to handle patients.' Additionally, lecturer IT02 chooses oral feedback in the form of a debriefing session to discuss the good practices and common mistakes with the students, as 'face to face feedback is more convenient for students to obtain comments on their work.' As for AS02, he tries to be 'as Socratic as possible so they come and ask me a question, I'll ask them a follow up question.'

In this regard, $\mathrm{AS} 02$ has a very strange approach to make his students take responsibility in their actions, he wants the students to think of all the possible consequences of their decisions and even 'allow them to suffer the consequences if they are bad decisions that they haven't thought something through.' The diversity of the lecturers' reasons to provide feedback is particularly striking. In the case of AS03, he points out his students' strengths and weaknesses where he explains 'I don't just tell them what is wrong, I also tell them what they are doing right.' He wants his students to learn from the feedback and not to focus on the marks, he states 'I always tell them when I return the submissions to them, hopefully they will use that my painstakingly written remarks to improve on their next assessment.' In contrast, BU01 is more concerned with giving feedback leading to high distinction (HD), she says 'generally, I will tell the student, a HD answer, what are the requirements.'

The nature of feedback varies among the lecturers. For examples, BU01 caters for individual feedback, which is a two-way interaction, where else IT02 provides feedback that is comprehensive, and it covers a wide range of issues. AS03 claims that 'feedback is always based on the assessment rubrics their strengths and weaknesses are pointed out.' However, with reference to AS02 feedback, one can observe that he is trying to teach his students to learn from mistakes. He says 'I want them to make mistakes and try things and not me beforehand telling them the right things.' As a result, AS02 manipulates feedback to support learning.

As for corrective advice, Table 1 shows that AS03 uses feedback to reflect more than usually on cognition than on marks. However, the reflection is quite shallow and limited to a statement like 'it is formative, so one leads to another and to the other.' In other words, it implies that the formative nature of feedback may take the students to the next level of learning. 
Table 1. Overview of feedback categories in the soft-pure discipline

\begin{tabular}{|c|c|c|c|c|c|c|c|}
\hline \multirow[b]{2}{*}{ Lecturer } & \multicolumn{4}{|c|}{ Focus of Feedback } & \multirow{2}{*}{$\begin{array}{c}\text { Outlooks of Feedback } \\
\text { IF }\end{array}$} & \multicolumn{2}{|c|}{ Preferences of Feedback } \\
\hline & $\mathrm{TF}$ & $\mathrm{RF}$ & NF & $\mathrm{CA}$ & & $\mathrm{D} / \mathrm{IT}$ & $\mathrm{PD}$ \\
\hline MP01 & & & & & & $\mathrm{D}$ & \\
\hline IT02 & & & & & & $\mathrm{D}$ & \\
\hline $\mathrm{AS} 02$ & & & & & & IT & \\
\hline $\mathrm{AS} 03$ & & & & & & $\mathrm{D}$ & \\
\hline BU01 & & & & & & $\mathrm{D}$ & \\
\hline
\end{tabular}

Note. TF (types of feedback); RF (reasons for feedback); NF (nature of feedback); CA (corrective advice); IF (informal feedback); D/IT (dialogue or information transmission); PD (peer dialogue).

In the outlooks of feedback category, the interview data reveal that only MP01 and AS03 have a good understanding of informal feedback as in peer collaboration. To illustrate, in AS03 tutorial class students are encouraged to challenge and contest each other about their views. He creates 'a learning atmosphere where students also learn from each other' and he guides them into constructive conversations. More interesting, MP01 takes another approach, she claims 'I can say that their best guides are from their seniors, since the students can communicate freely and have the same experiences.'

Finally, for the preferences of feedback category, Table 1 reveals that class size is a significant factor to consider when choosing between dialogue and information transmission. BU01 believes that 'class size, perhaps like 30, then a dialogue, an individual dialogue is very ideal because there and then we know what the students are thinking.' Here, AS02 agrees and he adds time constraint as another factor where he complains 'there is just not enough hours in a day' to initiate dialogue with 120 students. In addition to identifying dialogue between lecturers and students, AS03 and MP01 also encourage student-to-student dialogue. Specifically, AS03 states 'I engage them a lot in role-play and debates,' and he continues 'even when I don't do that, during the tutorial, students are encouraged to challenge and contest each other about their views.' Likewise, MP01 students have many opportunities to learn and communicate with each other and when they have questions, MP01 says 'my approach is to direct students to where they can find the answer' by countering questions with questions.

\subsection{Soft-Applied Discipline}

In the soft-applied discipline, Table 2 displays a total agreement among the lecturers in choosing dialogue over information transmission as a means of feedback. It is important to note here that as in the soft-pure discipline, two lecturers promote peer dialogue. Even though lecturers are active in the focus of feedback category, there is a need to improve the implementation of informal feedback and corrective advice.

Table 2. Overview of feedback categories in the soft-applied discipline

\begin{tabular}{|c|c|c|c|c|c|c|c|}
\hline & \multicolumn{4}{|c|}{ Focus of Feedback } & \multirow{2}{*}{$\frac{\text { Outlooks of Feedback }}{\text { IF }}$} & \multicolumn{2}{|c|}{ Preferences of Feedback } \\
\hline Lecturer & $\mathrm{TF}$ & $\mathrm{RF}$ & $\mathrm{NF}$ & $\mathrm{CA}$ & & $\mathrm{D} / \mathrm{IT}$ & $\mathrm{PD}$ \\
\hline PH03 & & & & & & $\mathrm{D}$ & \\
\hline MP02 & & & & & & D & \\
\hline MP03 & & & & & & $\mathrm{D}$ & \\
\hline IT03 & & & & & & $\mathrm{D}$ & \\
\hline BU02 & & & & & & $\mathrm{D}$ & \\
\hline
\end{tabular}

Note. TF (types of feedback); RF (reasons for feedback); NF (nature of feedback); CA (corrective advice); IF (informal feedback); D/IT (dialogue or information transmission); PD (peer dialogue).

Information about the types of feedback is used as a starting point for the focus of feedback category. Here, overall, there is a good mix between oral and written feedback. MP03 relies on oral advice because 'most concepts are taught in group discussions'. Further, PH03 gives one-to-one formative feedback to her students. There remains, however, the written feedback from BU02 where she claims that 'I give very detailed feedback on each section of 
the assignment.' In addition, IT03 concentrates on coding and he leaves it to the students to 'to make use of the feedback for their higher order learning.' MP02 uses technology to post 'texts in chat rooms such as WhatsApp groups' in order to keep the students up-to-date and informed.

Some lecturers have very good reasons to give feedback to the students. For example, MP03 uses a feedback loop to stay in touch with her students and to be 'constantly aware of what the students think or how they are.' Of note, MP02 utilises feedback in support of learning and assessment where she determines 'the quality of their work, as well as their contributions to the team.' Furthermore, IT03 communicates 'the how, when and why of coding in a particular context' through feedback he gives to his students. Sadly, there are lecturers who still believe in giving feedback to justify marks awarded to the students. For example, BU02 says 'justifying the marks that I give them,' and PH03 explains why some students 'get fewer marks compared to the peers.'

The results of the analysis shown in Table 2 indicate that for the nature of feedback, both PH03 and MP03 go for individualised feedback and PH03 adds, 'I go for one-on-one feedback, for those students who really need improvement.' Furthermore, for problem-based learning, MP02 teaches the students 'how to work in a team through feedback.

It is a very good thing, especially in lecturers giving extra attention in the context of corrective advice. For example, PH03 says 'I sit down with them and re-clarify any ambiguity or confusion about the specific thing.' MP03 concurs 'Overall, I keep an eye on everyone's contributions to the group and apply appropriate advice or feedback to taking learning to the next level.' Likewise, BU02 wants her students to 'be more critical in thinking and how they can do better the next time.'

As can be seen from Table 2, most lecturers fail to comprehend what informal feedback entails in the outlooks of feedback category. The qualitative findings show that only two lecturers practise it with their students. MP02 allows her students to 'talk to their peers, or most of the time, their seniors to develop their own lessons.' In so doing, students are 'more aware of their strengths and weaknesses, or identify some of their more personal problems.' In a similar vein, MP03 conducts group-based teaching and she believes students' participation in the group work is crucial; hence, 'peers are better suited to monitoring their progress.' She takes informal feedback a notch higher to peer assessment of an oral presentation. Here, she says 'not only do the students who are listening to the presentations required to assess their peers; they themselves are also assessed on how much they have learned from the presentation.'

The analysis reveals that in the preferences of feedback category, all the lecturers choose dialogue. Interestingly, MP02 says 'I aim to develop the students to be professionals, and this process can be facilitated only by constant guidance and feedback in dialogue.' She practises Problem-based Learning (PBL) and her students are constantly involved in peer dialogue. She adds 'we integrate the studies based on lectures into group discussions.' Similarly, in MP03 class, during the weekly Student-project Cases (SPC) meetings, she constantly updates them on their progress and students receive informal feedback from their peers. In addition, MP03 adds that it is important for the lecturers to learn what students think, then use dialogue to 'instigate inquiry in their thought process, so that the students constantly question themselves.' Two lecturers PH03 and IT03 agree that dialogue is a two-way communication between lecturers and students. They agree that 'students tend to be more comfortable describing a particular practical/conceptual issue.' One lecturer, BU02 is quite flexible and innovative that she converts the tutorial session into a workshop and she starts 'conversing with the students on what do they think of the questions and how they plan to answer.'

\subsection{Hard-Pure Discipline}

Accepting dialogue is the preferred mode of feedback among the lecturers in this discipline, Table 3 also highlights two lecturers extend it to peer dialogue that is ubiquitous in informal feedback. Still though, both informal feedback and corrective advice need improvement, as they are relatively underutilised. In what follows, this paper provides detailed analysis of the interviews with quotes from the lecturers. 
Table 3. Overview of feedback categories in the hard-pure discipline

\begin{tabular}{|c|c|c|c|c|c|c|c|}
\hline & \multicolumn{4}{|c|}{ Focus of Feedback } & \multirow{2}{*}{$\begin{array}{c}\text { Outlooks of Feedback } \\
\text { IF } \\
\end{array}$} & \multicolumn{2}{|c|}{ Preferences of Feedback } \\
\hline Lecturer & $\mathrm{TF}$ & $\mathrm{RF}$ & NF & $\mathrm{CA}$ & & $\mathrm{D} / \mathrm{IT}$ & $\mathrm{PD}$ \\
\hline $\mathrm{SC} 03$ & & & & & & $\mathrm{D}$ & \\
\hline PH01 & & & & & & $\mathrm{D}$ & \\
\hline EN07 & & & & & & D & \\
\hline
\end{tabular}

Note. TF (types of feedback); RF (reasons for feedback); NF (nature of feedback); CA (corrective advice); IF (informal feedback); D/IT (dialogue or information transmission); PD (peer dialogue).

In the focus of feedback category, EN07 uses oral feedback for his students to self-evaluate 'based on their solutions and their scores. In another case, $\mathrm{SC} 03$ is more concerned with assessment, he utilises oral feedback to 'improve and check that they understand the concept.' PH01 concurs with SC03 and explains 'I focus on those questions that most of the students got them wrong.' Surprisingly, the link between assessment and feedback is quite strong for this discipline.

Regarding the reasons for feedback, they are mainly for improvement in assessment scores. For instance, PH01 says 'the ultimate outcome is to allow the students to know their weakness and correct it before the next assessment.' Similarly, SC03 shares the reason for feedback, explains 'We will discuss why that is the correct answer and the rest is not the desired answers.' From the above perspective, on the other hand, EN07 wants his students to discuss and act on the feedback to take it to the next level; he says 'I would write few sentences on the area that the students should concentrate more, or to get more knowledge about those particular topics.'

Information from the reasons of feedback, particularly from EN07, is used as a starting point in the nature of feedback. Here, feedback is used as a tool for peer learning as in 'students can reflect their work, know their mistakes and what they should do in order to improve' and it is also used by EN07 to support peer assessment 'justify your marks, like why you give $3 / 5$ for this section.' In what follows, SC03 organises his feedback in an interactive manner where 'suggestions provided are based on the answers they reply.' Interestingly, PH01 also employs 'two-way communication,' in giving feedback to the students where she says 'I would like to hear some feedback from the students.'

Regarding corrective advice to students, EN07 developed a unique way where he relies on the students' peer assessment and group reflection. Here, advice is given to the group so that 'after reading the comments, they would know their mistakes.' On the other hand, SC03 advises his students when he interacts with them informally and he has confidence in this approach as the 'students can have more independence in learning.'

In the outlooks of feedback area, Table 3 displays that EN07 practises informal feedback where he gives 'some time for the students to discuss with their friends.' This is because he understands that 'every student is different and they have different knowledge.' More interestingly, he takes note that students are more or less of the same age, hence they are 'comfortable to get additional insights from their friends, then to ask the lecturers or the tutors' questions.' The same strategy applies in the tutorial class, that is, students have to 'discuss the questions with their friends to come up with the solutions' before they approach the lecturer and the tutors for assistance.

Another example is mentioned by SC03, who says 'informal feedback is given by the lab demonstrators' and also in a less formal setting, students tend to be 'more interactive and give suggestions based on the answers received.' Unfortunately, the rest of the lecturers take informal feedback as a venue to report 'uneven workload, contributions to the project, and what problems they have faced throughout the project.'

Finally, in the preferences of feedback, lecturers' choice is dialogue over information transmission. Accordingly, it would be beneficial to note that peer feedback may play a significant role in learning. EN07 explains how he engages senior students in the Peer Assisted Self-learning (PASL) programme to provide additional support in student learning. He believes 'students are more comfortable with their seniors than their lecturers.' In other words, students may 'ask their seniors more questions, such as their experiences doing this unit previously.' Likewise, SC03 allows 'peers to help one another to answer certain questions,' he reasons, is better than just listening to him talking most of the time. Moreover, dialogue as a tool to facilitate communication among students and between lecturers and students, PH01 advocates it is an attractive tool to 'give a chance for the students to voice out their opinions or to ask further questions.' 


\section{4 Hard-Applied Discipline}

The results of the analysis shown in Table 4 shows a trend quite similar to that in Table 3 for the hard-pure discipline. In other words, most lecturers indicate they prefer a dialogue mode of feedback with two of them also advocate peer dialogue. Importantly, the analysis highlights the need for more emphasis on informal feedback and corrective advice.

Table 4. Overview of feedback categories in the hard-applied discipline

\begin{tabular}{|c|c|c|c|c|c|c|c|}
\hline & \multicolumn{4}{|c|}{ Focus of Feedback } & \multirow{2}{*}{$\begin{array}{c}\text { Outlooks of Feedback } \\
\text { IF }\end{array}$} & \multicolumn{2}{|c|}{ Preferences of Feedback } \\
\hline Lecturer & $\mathrm{TF}$ & $\mathrm{RF}$ & NF & $\mathrm{CA}$ & & $\mathrm{D} / \mathrm{IT}$ & PD \\
\hline EN01 & & & & & & $\mathrm{D}$ & \\
\hline EN03 & & & & & & $\mathrm{D}$ & \\
\hline BU03 & & & & & & $\mathrm{D}$ & \\
\hline BU04 & & & & & & $\mathrm{D}$ & \\
\hline BU05 & & & & & & IT & \\
\hline
\end{tabular}

Note. TF (types of feedback); RF (reasons for feedback); NF (nature of feedback); CA (corrective advice); IF (informal feedback); D/IT (dialogue or information transmission); PD (peer dialogue).

In the focus of feedback category, the majority of lecturers provide written feedback; BU03 leaves 'comments throughout the whole assignment and email students a copy.' Sadly, BU04 equates feedback to marks; he says 'the first direct feedback given to students is the marks for their mid-semester examination.' Apparently, BU05 shares the view of BU04 on feedback; she explains 'the most important point in every question as well as the examination terminologies with my students.' On the other hand, technically EN03 does not provide feedback to the students, the laboratory demonstrators are the ones that offer 'oral guidance given on the spot.' Further, EN01 offers communicative feedback where he challenges his students to 'participate, discuss and to ask questions.'

Regarding the reasons to give feedback, BU05 wants the students to focus on 'answering the question rather than wasting time trying to figure out the requirements.' Strangely, this lecturer believes in this manner it will help students to 'improve their performance in examinations.' Another lecturer, BU04 also focuses on marks and examination he tries to 'identify the "high risk" students and try to help them to pass the final examination.' As for BU03 and EN03 feedback is to avoid making the same mistakes and to 'highlight their strengths and weaknesses.' However, with reference to EN01 reason for feedback, one can argue that he favours self-learning. This is because he says 'my feedback for them would often be corrective advice that can direct the students to think critically and creatively.' He thinks it makes more sense for the students to 'learn it themselves, instead of me telling them what to do.'

From the nature of feedback perspective, BU05 arranges for weekly feedback and she is glad that 'the students did actually take note of those and improve on their reflective notes afterwards.' Other diverse natures of feedback are, for example, BU03 shows the whole class every group' assignments so that 'the students are aware of the common mistakes made by their peers.' In particular, EN01 uses feedback to activate students' prior knowledge so that they can connect it to the existing ideas by drawing in 'other examples from existing building on how they are design in a particular way.' Additionally, EN03 makes use of feedback in the laboratory exercises which, are hierarchical to ensure students 'understand their mistake and improve from that,' before moving on to the next exercise.

Data gathered through interview indicate that EN01 offers corrective advice to his students who are engaged 'in lectures by participating, discussing and asking questions that can help them in their design.' In other words, his students have to be actively involved in the learning process in order to reap the benefits of his advice as he does not 'advocate spoon-feeding in any occasion.'

Table 4 shows in the outlooks of feedback category, EN03 students collaborate with their peers in informal feedback to discuss the solutions. They are free to 'ask their seniors as well, who may help them out, but eventually the answers have to be written from the students' points of view. Apparently, the purpose of this informal feedback is directed at assignment. Nevertheless, students still participate in 'detailed discussion through peer interactions.' Regarding informal feedback in BU04 class, it happens during question-and-answer session after oral presentations and he adds 'I found out that students are able to give very good feedback.' Still though, from the other three discipline clusters, the interview data clearly indicate that informal feedback is not the lecturers' 
popular choice.

Among the choices in the preferences of feedback category, dialogue still dominates over information transmission. Specifically, EN03 uses dialogue because 'there is interaction to ensure students engage and understand the concept.' Most importantly, this engagement is extended to include 'collaboration with their peers and their seniors as well.' Very similarly, in BU04 class, students work in groups during the workshops and 'the high achievers are helping the academically weak ones.' From the information transmission perspective, it is BU05's choice because according to her 'students need to take things seriously,' indicating that for students to take note, feedback or comments must be written down clearly. Regarding the other lecturers, dialogue is used in debriefing (BU03), and in consultation session (EN01).

\section{Discussions}

In seeking to understand, the lecturers' perspectives on feedback across different disciplines, many interesting and surprising findings surfaced. The key findings in the results are used as a means to providing a rationale for the recommendations.

According to Archer (2010), the socio-constructivist feedback is more facilitative, involving dialogue among the peers to act on the comments and suggestions given in order to come up with new understanding. In the present study, the lecturers' choice of feedback is also dialogue, but it is mostly from the lecturers to the students in order to assist them in improving their learning and to correct wrong answers. Among the four discipline clusters, only two lecturers from each cluster facilitate student peer dialogue in informal feedback. Unsurprisingly, there is also resistance to peer feedback from students and lecturers in other studies (Dawson et al., 2019). Nevertheless, according to EN07 from the hard-pure cluster, peer dialogue shows up in the Peer Assisted Self-learning (PASL) programme. Interestingly, peer dialogue happens under different situations in SC03 class. He practises student-centred approach where his students give comments and suggestions when they interact with each other and with the learning activities. Of note, between these two lecturers, it is reasonable to assume that they advocate socio-constructivist feedback as described by Archer (2010). Even though there is a significant indication here, the interview data do not lead to any serious evidence that hard-pure lecturers practise socio-constructivist feedback.

Speaking of hard-applied discipline, it is also possible to see student peer dialogue being practised in EN03 and BU04 classes. Importantly, from an instructional perspective, BU04 conducts weekly group-based workshops where students have the opportunities to interact with their peers. Very similarly, EN03 follows the Peer Assisted Study Sessions (PASS) procedures in getting his students to learn from one another. In the context of the present study, the lecturers' teaching methods, as well as peer assisted programmes used, not to mention the lecturers' role in supporting peer learning and in the design of learning activities, may have played some part in choosing the socio-constructivist feedback. As such, the current study considers these factors when reflecting on the research question, 'is the choice of the feedback model related to discipline?' Further, to facilitate discourse and to bring about more insights into possible responses to the research question, the discussion is now shifted to the other two clusters of discipline, namely soft-pure and soft-applied. As for AS03 from the soft-pure discipline, overall, he uses a variety of learning activities to engage his students. Consequently, through these activities, students attempt to co-construct meanings from the feedback they received from the lecturers or from the databank of feedback comments (Carless \& Boud, 2018). Therefore, it is reasonable to state there is evidence of the presence of socio-constructivist feedback. This statement suggests the pedagogical approach used by AS03 rather than the discipline cluster he belongs to leads to the choice of feedback. More interestingly, from the teaching perspective, MP02 and MP03 from the soft-applied discipline also utilise student-centred strategies, PBL for MP02 and SPC for MP03. Therefore, it is theoretically plausible to state the choice of feedback model, particularly; socio-constructivist feedback may not be related to discipline.

Generally, the interview evidence indicates that in every cluster of disciplines the reasons for feedback from the lecturers include, among others, to justify marks awarded, to correct wrong answers, and to improve performance in examinations. In this regard, it is important to note that this group of lecturers favour the external provision of information in the form of feedback based on observable performance (Boud \& Molloy, 2013) and they believe this vague notion may lead to improvement (Dawson et al., 2019). To this end, from the feedback variants spectrum perspective, they are closer to the cognitivist feedback end of the spectrum. Accordingly, it would be beneficial to provide a feedback loop to generate continual information to meet the learning needs of the students. To serve this purpose, there is a need to reduce the class size to perhaps 30 (according to BU01). As such, it may be beyond the realm of lecturers, and although they do not request for the reduction, two lecturers from this group, SC03 and PH01, incorporate the "why" and "how" as well as understanding of concepts in the two-way interactive feedback to the students. Therefore, it is important to note that they may have helped their students to acquire at 
least two of the four features in the feedback literacy by Carless and Boud (2018). To illustrate, the students may appreciate feedback better as the wrong answers are explained in relation to the concepts and the interactive nature makes them recognise the value of feedback. In a similar vein, the lecturers can observe that students act upon the feedback they received (Sutton, 2012) and further comments may be given to reinforce the actions. To this end, a better understanding of feedback designs may be supportive of more agentic engagement with feedback (Winstone, Nash, Parker, \& Rowntree, 2017).

\section{Conclusions}

The importance of feedback to student learning is well known and the principles of effective feedback are well established. The findings of this study are significant as they provide the relationships between the feedback models and disciplines as well as whether lecturers practised socio-constructivist feedback. Even though the research is conducted in one offshore university, the results may have particular values to universities practising collaborative learning in formal or informal learning spaces (virtual and physical).

The present study addresses the gap between the feedback models and discipline clusters. The diversity of the lecturers' views and comments obtained through interviews poses a challenge in closing the gap. The results reveal that there is no evidence to link discipline to the choice of feedback model. In the context of feedback spectrum and in terms of discipline clusters, lecturers irrespective of discipline prefer the cognitivist as well as the socio-constructivist ends of the spectrum and it includes feedback variants between the two extremes. In other words, with regard to the first research question, yes, they do practise socio-constructivist feedback and other models too. The findings of this study suggest the pedagogical approach leads to the choice of feedback rather than the discipline clusters. Nevertheless, the findings are limited to 31 lecturers from one university. For further study, the sample size may be extended to include lecturers from the public and private universities.

Interestingly, there has been a recent emphasis on community learning and services through the community of inquiry framework (Kozan \& Caskurlu, 2018) thereby highlighting the importance of socio-constructivist feedback and collaborative learning. As a result, future research may look into how the individual and group-level learning activities intertwined with the social presence of the framework resulting in productive collaborative learning and socio-constructivist feedback.

\section{Acknowledgements}

This work was supported by funding from the Science, Technology and Society Cluster, Global Asia in the 21st Century (GA21), a campus funded multidisciplinary research platform of Monash University Malaysia (grant number GA/TM-16-S01). The funding source has no involvement in the research and the writing of this article.

\section{References}

Arbaugh, J. B. (2005). How much does "subject matter" matter? A study of disciplinary effects in online MBA courses. Academy of Management Learning \& Education, 4, 57-73. https://doi.org/10.5465/amle.2005.16132549

Arbaugh, J. B., \& Rau, B. L. (2007). A study of disciplinary, structural, and behavioural effects on course outcomes in online MBA courses. Decision Sciences Journal of Innovative Education, 5, 63-93. https://doi.org/10.1111/j.1540-4609.2007.00128.x

Arbaugh, J. B., Bangert, A., \& Cleveland-Innes, M. (2010). Subject matter effects and the community of inquiry framework: An exploratory study. The Internet and Higher Education, 13(1-2), 37-44. https://doi.org/10.1016/j.iheduc.2009.10.006

Archer, J. C. (2010). State of the science in health professional education: Effective feedback. Medical Education, 44, 101-108. https://doi.org/10.1111/j.1365-2923.2009.03546.x

Biglan, A. (1973). The characteristics of subject matter in different academic areas. Journal of Applied Psychology, 57(3), 195-203. https://doi.org/10.1037/h0034701

Boud, D., \& Falchikov, N. (2007). Assessment for the longer term. In D. Bound, \& N. Falchikov (Eds.), Rethinking Assessment in Higher Education (pp. 3-13). London: Routledge. https://doi.org/10.4324/9780203964309

Boud, D., \& Molloy, E. (2013). Rethinking models of feedback for learning: The challenge of design. $\begin{array}{llll}\text { Assessment \& Evaluation in Higher Education, 38(6), 698-712. } & \text {. }\end{array}$ https://doi.org/10.1080/02602938.2012.691462

Carless, D., \& Boud, D. (2018). The development of student feedback literacy: Enabling uptake of feedback. 
Assessment \& Evaluation in Higher Education, 43(8), 1315-1325. https://doi.org/10.1080/02602938.2018.1463354

Carless, D., Salter, D., Yang, M., \& Lam, J. (2011). Developing sustainable feedback practices. Studies in higher Education, 36(5), 395-407. https://doi.org/10.1080/03075071003642449

Dawson, P., Henderson. M., Mahoney, P., Phillips, M., Ryan, T., Boud, D., \& Molloy, E. (2019). What makes for effective feedback: Staff and student perspectives. Assessment \& Evaluation in Higher Education, 44(1), 25-36. https://doi.org/10.1080/02602938.2018.1467877

Feibleman, J. K. (1972). Pure science, applied science, and technology: An attempt at definition. In C. Mitcham, \& R. Mackey (Eds.), Philosophy and Technology: Readings in the Philosophical Problems of Technology (pp. 33-41). New York, NY: Collier Macmillan.

Gale, N. K., Heath, G., Cameron, E., Rashid, S., \& Redwood, S. (2013). Using the framework method for the analysis of qualitative data in multi-disciplinary health research. BMC Medical Research Methodology, 13. https://doi.org/10.1186/1471-2288-13-117

Garrison, D. R., \& Cleveland-Innes, M. (2005). Facilitating cognitive presence in online learning: Interaction is not enough. The American Journal of Distance Education, 19(3), 133-148. https://doi.org/10.1207/s15389286ajde1903_2

Hounsell, D. (2007). Towards more sustainable feedback to students. In D. Boud, \& N. Falchikov (Eds.), In Rethinking Assessment in Higher Education (pp. 101-113). London: Routledge.

Kozan, K., \& Caskurlu, S. (2018). On the nth presence for the community of inquiry framework. Computers \& Education, 122, 104-118. https://doi.org/10.1016/j.compedu.2018.03.010

McHugh, M. L. (2012). Interater reliability: The kappa statistic. Biochemia Medica, 22(3), $276-282$. https://doi.org/10.11613/BM.2012.031

Nicol, D. (2010). From monologue to dialogue: Improving written feedback in mass higher education. Assessment \& Evaluation in Higher Education, 35(5), 501-517. https://doi.org/10.1080/02602931003786559

Nicol, D., \& Macfarlane-Dick, D. (2007). Formative assessment and self-regulated learning: A model and seven principles of good feedback practice. Studies in Higher Education, 31(2), 199-218. https://doi.org/10.1080/03075070600572090

Nicol, D., Thomson, A., \& Breslin, C. (2014). Rethinking feedback practices in higher education: A peer review perspective. Assessment \& Evaluation in Higher Education, 39(1), $102-122$. https://doi.org/10.1080/02602938.2013.795518

Price, M., Handley, K., \& Millar, J. (2011). Feedback: Focusing attention on engagement. Studies in Higher Education, 36(8), 879-896. https://doi.org/10.1080/03075079.2010.483513

Sutton, P. (2012). Conceptualizing feedback literacy: Knowing, being, and acting. Innovations in Education and Teaching International, 49(1), 31-40. https://doi.org/10.1080/14703297.2012.647781

Vanslambrouck, S., Zhu, C., Pynoo, B., Thomas, V., Lombaerts, K., \& Tondeur, J. (2019). An in-depth analysis of adult students in blended environments: Do they regulate their learning in an 'old school' way? Computer and Education, 128, 75-87. https://doi.org/10.1016/j.compedu.2018.09.008

Wingate, U. (2010). The impact of formative feedback on the development of academic writing. Assessment \& Evaluation in Higher Education, 35(5), 519-533. https://doi.org/10.1080/02602930903512909

Winstone, N. E., Nash, R.A., Parker, M., \& Rowntree, J. (2017). Supporting learners' agentic engagement with feedback: A systematic review and a taxonomy of recipience processes. Educational Psychology, 52(1), 17-37. https://doi.org/10.1080/00461520.2016.1207538

\section{Copyrights}

Copyright for this article is retained by the author(s), with first publication rights granted to the journal.

This is an open-access article distributed under the terms and conditions of the Creative Commons Attribution license (http://creativecommons.org/licenses/by/4.0/). 